\title{
Experimental Evaluation of Activated Termite Mound for Fluoride Adsorption
}

\author{
Fekadu Fufa \\ School of Civil and Environmental Engineering, Jimma Institute of Technology, Jimma University, Oromia, \\ Ethiopia
}

\begin{abstract}
The main objective of this study was to examine fluoride adsorption potential of thermally activated termite mound (TTM) under batch adsorption experimentalsetup. Thermal activation of the mound in between 100 to $500^{\circ} \mathrm{C}$ increased the adsorption efficiency $(\sim 50$ to $\sim 79 \%)$, whereas activation above $500^{\circ} \mathrm{C}$ decreased the efficiency. The removal of fluoride was optimal ( 91\%) in the pH ranging from 3 to 10. Adsorption kinetics data followed pseudo-second order equation $\left(R^{2}>0.99\right)$. Freundlich and Dubinin-Radushkevich isotherms satisfactorily described the equilibrium isotherm data $\left(R^{2}>0.98, \chi^{2}<0.25\right)$. The obtained mean sorption energy, $E_{D R}$, was $11.12 \mathrm{~kJ} / \mathrm{mol}$ suggesting chemisorption as the predominant sorption mechanism. Fluoride adsorption was significantly decreased in the presence of $\mathrm{CO}_{3}{ }^{2-}$ and $\mathrm{PO}_{4}{ }_{4}^{3-}$ at a higher concentration range. TTM effectively reduced $7.56 \mathrm{mg} / \mathrm{L}$ fluoride in groundwater to below $1.5 \mathrm{mg} / \mathrm{L}$. Fluoride loaded adsorbent was successfully regenerated with $\mathrm{NaOH}$ solution for effective reuse. The results of this study demonstrated that TTM could be a promising defluoridation material requiring further investigation for practical applicability.
\end{abstract}

Keywords: Sorption energy, TTM;Thermal activation;Equilibrium;Termite mound

\section{Introduction}

Fluoride in drinking water may be useful or harmful depending on the amount ingested. A small concentration $(1-1.5 \mathrm{mg} / \mathrm{L})$ is believed to strengthen the enamel. However, the debate over the health benefits of fluoride even at low concentrations is rising [1]. Fluoride levels in the range of 1.5-4 mg/L can cause dental fluorosis, whereas with prolonged consumption of higher fluoride concentrations $(>4 \mathrm{mg} / \mathrm{L})$ dental fluorosis develops to skeletal fluorosis. Excess fluoride concentrations in groundwater, up to $20 \mathrm{mg} / \mathrm{L}$, occur widely in many parts of the world [2] including Ethiopia [3, 4]. The Main Ethiopian Rift Valley region is one of the fluorosis endemic regions of the world [5], where more than 8 million populations are exposed to high fluoride levels in the drinking groundwater[3, 4]. Consequently, the World Health Organization (WHO) as well as the Ethiopian Quality and Standard Authority set a guideline value of $1.5 \mathrm{mg} / \mathrm{L}$ for fluoride in drinking water $[5,6]$. However, the Ministry of Water Resources of Ethiopia, for many reasons, suggested the fluoride level in the drinking water at $3.0 \mathrm{mg} / \mathrm{L}$ [7]. Therefore, the search for simple, low-cost, efficient locally available adsorbent materials is an important in the development of defluoridation technique to reduceexcess fluoride in the drinking groundwater to acceptable levels.

There are several methods of fluoride removal, such as ion exchange, reverse osmosis, nanofiltration, electrodialysis and dialysis that effectively reduce fluoride concentrations to below acceptable level [2, 8-12]. However, these membrane techniques have inherent disadvantages for the practical application in the fluorosis endemic regions of the developing countries like Ethiopia. Although membrane methods are efficient, adsorption has been given priority in the defluoridaion research and practice for easier accessibility, costeffectiveness, and simplicity of design and operation[2]. Various investigations have been thus carried out to remove fluoride by adsorption technique using locally available materials, such as solid waste residue from alum factory [13], laterite [14], bauxite [15], allophanes [16], bone char [17], ceramics [18], gypsum [19] and many others.

Nevertheless, the practical applicability of locally available materials is limited due to their low sorption capacity, need for $\mathrm{pH}$ adjustment and dissolution problem. Hence, several studies have been conducted to enhance the sorption capacity through thermal activation. In this regard, researchers have observed improvement of the sorption capacity of various materials after thermal activation [15, 19-21]. As such, the sample of termite mound, containing mainly oxides of $\mathrm{Si}, \mathrm{Fe}, \mathrm{Al}$ and $\mathrm{Ti}$, was thermally activated at different temperatures before the adsorption experiments. Therefore, this study focused (1) to evaluate fluoride sorption capacity of activated termite mound under batch adsorption conditions;(2) to examine the trend of fluoride adsorption with respect to variation of activation temperature, solution $\mathrm{pH}$, adsorbent dose, initial fluoride concentration, and initial concentration of competing anions; and (3) to investigate the reusability of fluoride loaded adsorbent. 
Adsorbent:

\section{Materials and Methodology}

In Ethiopia termite mounds are abundantly found. Particularly, in 8 districts of east and west Wallaga Zones in Oromia Regional National State infestation of mound building termites is has become serious problem for the local farmers [22]. In the southern and western parts of Ethiopia, average mound abundance was found to be 12 mound hills/ha [23, 24], and the estimated mound soil mass is 58.9 t/ha [23]. Six samples of mound soil were collected from 6 termite mounds in the surroundings of Gimbi, (36 P 1036902E 815766N), west Wallaga Zone, Oromia Regional National State, western Ethiopia. A composite sample was made mixing thoroughly the six samples in an equal proportion, and dried afterwards at room temperature. Particle size analysis of the composite sample was performed according to the American Society for Testing and Materials (ASTM D 422) and soil textural classification system [25]. The moisture content was determined heating in an oven at $105^{\circ} \mathrm{C}$ for $24 \mathrm{~h}$. The $\mathrm{pH}$ of the adsorbent was measured using a Microprocessor $\mathrm{pH} 196$ meter (pH 196, WTW, Germany) in a 1:10 soil/water ratio according to the standard method [26]. The $\mathrm{pH}$ of the point of zero charge $\left(\mathrm{pH}_{\mathrm{PZC}}\right)$ of untreated mound soil was determined by the potentiometric titration method [27]. Oxides and elemental compositions were analyzed using X-Ray Fluorescence (XRF) spectrometry and inductively coupled plasma spectrometer (ICP, Thermo Scientific iCAP 6300 Inductively Coupled Plasma Spectrometer), respectively. Total carbon, total nitrogen and total sulfur contents were determined using Elementar Vario EL analyser (Elementar Analysensysteme GmbH, Hanau, Germany) according to DIN ISO 10694 and 13878 [28, 29]. Surface area of untreated and heat treated mound soil of particle size $<0.075 \mathrm{~mm}$ were determined by BET method using Micromeritics (ASAP 2010, USA) after degassing.

\section{Thermal Activation:}

Earlier investigations [15, 19-21] show that thermal activation influences fluoride adsorbing capacity of adsorbents. As such, a weighed amount of air dried composite sample of raw termite mound was thermally heated in between 100 and $800^{\circ} \mathrm{C}$ for $4 \mathrm{~h}$ in a preheated furnace. The calcined sample was crushed, sieved to particle size $<0.075 \mathrm{~mm}$ and stored in airtight plastic bottles before adsorption experiments. The weight after calcination was taken to calculate the loss of water and other volatile substances.

\section{Preparation of Desorbent Solution:}

The study conducted by Thongthai [30] indicates that egg shell calcined in a preheated furnace at $900^{\circ} \mathrm{C}$ for $3 \mathrm{~h}$ contains $\sim 97 \% \mathrm{CaO}$. To prepare $\mathrm{CaO}$, the egg shell was washed with deionized water, and dried in an oven at $105^{\circ} \mathrm{C}$ for $24 \mathrm{~h}$. The dried egg shell was milled by hand using a mortar for calcination at $900^{\circ} \mathrm{C}$ for $3 \mathrm{~h}$ in a preheated furnace [31,32]. The calcined egg shell was cooled in a desiccator. To prepare an alkaline solution of $\mathrm{Ca}(\mathrm{OH})_{2}, 100 \mathrm{~g}$ of the powder of calcined egg shell was stirred in $1 \mathrm{~L}$ deionized water and filtered to remove undissolved matter. Then the supernatant solution of $\mathrm{Ca}(\mathrm{OH})_{2}$ labeled "CES solution" having $\mathrm{pH} 12.27$ was used for fluoride desorption.

\section{Chemicals:}

All chemicals used were analytical grade reagent of the Merck product, Damstadt, Germany. A 1000 $\mathrm{g} / \mathrm{L}$ fluoride stock solution was prepared by dissolving $2.21 \mathrm{~g}$ anhydrous $\mathrm{NaF}$ in $1 \mathrm{~L}$ of deionized water. Working solutions of fluoride were prepared from the stock solution by dilution using deionized water. The solutions of $\mathrm{HCO}_{3}{ }^{-}, \mathrm{CO}_{3}{ }^{2-}, \mathrm{Cl}^{-}, \mathrm{NO}_{3}{ }^{-}, \mathrm{SO}_{4}{ }^{2-}$ and $\mathrm{PO}_{4}{ }^{3-}$ anions were prepared from their respective potassium salts. The $\mathrm{pH}$ of the solution was adjusted using $0.1 \mathrm{M} \mathrm{NaOH}$ and/or $0.1 \mathrm{M} \mathrm{HCl}$. A $1000 \mathrm{mg} / \mathrm{L}$ standard solution of fluoride was used to calibrate the ion chromatography.

\section{Adsorption Experimental Procedures:}

Batch adsorption experiments were carried out in acid washed high density polyethylene (HDPE) plastic bottles using a desired fluoride concentration and dose of TTM. All the experiments were conducted in duplicate at room temperature $\left(23.5\right.$ to $\left.25.5^{\circ} \mathrm{C}\right)$. Average data of the duplicate measurements were reported. Blank (only with TTM) and control (only with fluoride) experiments were conducted at every set of the experiments. After shaking $500 \mathrm{~mL}$ solution containing known concentration of fluoride and desired dose of adsorbent at $200 \mathrm{rpm}$ on a horizontal shaker for a desired time, the solid matter was separated by filtration with $0.45 \mu \mathrm{m}$ acetate filter paper. The concentration of fluoride in the filtrate was analyzed using double beam T80 UV-VIS spectrophotometer (PG Instruments, UK).

Experimental parameters, such asvarying contact time, dose of TTM, pH of the solution, initial concentration of fluoride and the presence of interfering anions were investigated to assess the effect on fluoride adsorption, and optimize the adsorption process for maximum fluoride removal. The effect of contact time was studied varying the agitation time from 0 to $60 \mathrm{~min}$ at $\mathrm{pH} 7$ using $12 \mathrm{~g} / \mathrm{L}$ TTM in $500 \mathrm{~mL}$ solution of $10 \mathrm{mg} / \mathrm{L}$ fluoride. The adsorption kinetic was examined varying the concentration of fluoride ( 5 to $25 \mathrm{mg} / \mathrm{L}$ ) and the dose 
of adsorbent ( 5 to $30 \mathrm{~g} / \mathrm{L}$ ) while keeping the other conditions constant. The pattern of the efficiency of fluoride removal under different initial solution $\mathrm{pHs}$ was investigated in the $\mathrm{pH}$ range $\sim 3$ to $\sim 11$ using $10 \mathrm{mg} / \mathrm{L}$ fluoride and $12 \mathrm{~g} / \mathrm{L}$ TTM. The efficiency of fluoride adsorption by TTM was examined varying the amount of adsorbent from 1 to $28 \mathrm{~g} / \mathrm{L}$ under $10 \mathrm{mg} / \mathrm{L}$ fluoride at solution $\mathrm{pH} \sim 7$. The effect of varying the level of fluoride concentration on the fluoride removal was studied in the concentration range 3 to $155 \mathrm{mg} / \mathrm{L}$ at pH $\sim 7$ using 12 g/L TTM. To evaluate the influence of the presence of co-existing anions in water, 10 to $500 \mathrm{mg} / \mathrm{L}$ anion concentrations were used separately and in a mixture in $500 \mathrm{~mL}$ solution of $10 \mathrm{mg} / \mathrm{L}$ fluoride at solution $\mathrm{pH} \sim 7$. The fluoride sorption efficiency of $12 \mathrm{~g} / \mathrm{L}$ TTM was evaluated under identical batch adsorption setup using two samples of groundwater containing 7.56 and $15.93 \mathrm{mg} / \mathrm{L}$ fluoride, respectively.

The amount of fluoride adsorbed per unit mass of the adsorbent and the percentage of fluoride adsorbed were computed, respectively using Eq. (1) and Eq. (2) [33] shown below:

$q_{t}=\left(\frac{C_{0}-C_{t}}{M}\right) \times V(1) A \%=\left(\frac{C_{0}-C_{t}}{C_{0}}\right) \times 100$

where, $q_{t}(\mathrm{mg} / \mathrm{g})$ is the amount adsorbed at any time, $t(\mathrm{~min}), A(\%)$ is the percentage of fluoride adsorbed, $C_{o}(\mathrm{mg} / \mathrm{L})$ and $C_{t}(\mathrm{mg} / \mathrm{L})$ are the initial concentration of fluoride and the concentration of fluoride in the aqueous phase at any time, $t$,respectively, $V(\mathrm{~L})$ is the volume of the aqueous solution, and $M(\mathrm{~g})$ is the mass of TTM used in the experiments.

\section{Desorption Study}

To evaluate the regenerability of the spent TTM, a $10 \mathrm{mg} / \mathrm{L}$ of fluoride in the aqueous solution was initially allowed to adsorb on $12 \mathrm{~g} / \mathrm{L}$ TTM at $\mathrm{pH} \sim 7$ for $60 \mathrm{~min}$ by shaking the mixture. After adsorption, the solid was separated by filtration, dried at $105^{\circ} \mathrm{C}$ for $12 \mathrm{~h}$ in an oven, and then used for desorption study. Desorption investigations were conducted shaking at $200 \mathrm{rpm}$ for $60 \mathrm{~min}$ the dried fluoride loaded TTM with $500 \mathrm{~mL}$ solution of CES, 0.1 and $0.2 \mathrm{M} \mathrm{NaOH}$ separately. In addition, the $\mathrm{pH}$ of deionnized water was adjusted to $\sim 5$ to assess the release of fluoride ion from fluoride loaded adsorbent for safe disposal of the spent TTM at $\mathrm{pH} \leq 5$. The amount of fluoride desorbed from the solid into the solution was then determined analyzing the concentration of fluoride in the supernatant solution after desorption experiment.

The regenerated fluoride loaded adsorbent was rinsed with $0.1 \mathrm{M} \mathrm{HCl}$ until the $\mathrm{pH}$ of the supernatant solution was $\sim 5$, which is the $\mathrm{pH}$ of the fresh mound soil measured in 1:10 adsorbent/water ratio. Then, the dried regenerated TTMS was allowed to adsorb $10 \mathrm{mg} / \mathrm{L}$ fluoride for $60 \mathrm{~min}$ at solution $\mathrm{pH} \sim 7$ under batch adsorption setup.

\section{Analysis:}

After filtration to separate the solid particles, residual fluoride in the clear supernatant solution was measured using ion chromatography (Metrohm AG, Switzerland) with chemical suppression and a Metrosep Dual 2 column $(75 \mathrm{~mm})$. Calibration of the ion chromatography using a standard solution of fluoride was performed prior to each set of the analyses. Fluoride concentration was calculated on the basis of the peak area using a quadratic regression equation derived from the measurements of the standard solutions. The concentrations of elements were analyzed using an inductively coupled plasma spectrometer (ICP, Thermo Scientific iCAP 6300 Inductively Coupled Plasma Spectrometer).

\section{Characterization of Adsorbent:}

\section{Results and Discussion}

The chemical compositions, major oxides and some elements, of termite mound are given in Table $\mathbf{1 .}$ The $\mathrm{Si}, \mathrm{Fe}, \mathrm{AL}$ and $\mathrm{Ti}$ oxides together made up $85.60 \mathrm{wt} \%$, while basic metallic ( $\mathrm{Na}, \mathrm{Ca}, \mathrm{Mg}$ and $\mathrm{K}$ ) oxide contents were negligible $(\sim 1 \%)$. Silicon was the major elemental content of the adsorbent. The composition of $\mathrm{Si}+\mathrm{Fe}+\mathrm{Al}+\mathrm{Ti}$ elements amounted to $35.59 \mathrm{wt} \%$. Compositions of the analyzed toxic elements were below detection limit except for $\mathrm{Cr}$, which was $0.01 \mathrm{wt} \%$. The BET surface area of raw termite mound was found to be $28.40 \mathrm{~m}^{2} / \mathrm{g}$. The $\mathrm{pH}_{\mathrm{PZC}}$ of TM determined by the potentiometric titration method was found to be 7.96 . The obtained value of $\mathrm{pH}_{\mathrm{PZC}}$ is within the range of the $\mathrm{pH}_{\mathrm{PZC}}$ of the mixture of $\mathrm{Si}, \mathrm{Fe}, \mathrm{Al}$, and Ti oxides, 5.5 to 8.3 [34], and comparable to the $\mathrm{pH}_{\mathrm{PZC}}$ of termite mound $\left(\mathrm{pH}_{\mathrm{PZC}}=7.8\right)$ investigated for the removal of $\mathrm{Pb}$ (II) [35]. Total carbon, total sulfur and total nitrogen contents together constituted $2.60 \%$. The $\mathrm{pH}$ of uncalcined termite mound determined in water was 5.10. The moisture content of the raw mound soil was found to be $3.92 \%$. Particle size analysis showed that the majority of particles were in the range of $0.075-2.00 \mathrm{~mm}$ with mean particle size $\left(d_{50}\right)$ of $0.51 \mathrm{~mm}$.

Table 1. Chemical Composition of Raw Termite Mound

\begin{tabular}{|l|l|l|l|l|}
\hline Oxides & Wt\% & & Elements & Wt\% \\
\cline { 1 - 2 } & 27.43 & $\mathrm{Si}$ & 15.07 \\
\hline
\end{tabular}




\begin{tabular}{|l|l|l|l|l|}
\hline $\mathrm{Al}_{2} \mathrm{O}_{3}$ & 22.83 & & $\mathrm{Fe}$ & 12.67 \\
\hline $\mathrm{Fe}_{2} \mathrm{O}_{3}$ & 26.08 & & $\mathrm{Al}$ & 6.35 \\
\hline $\mathrm{TiO}_{2}$ & 8.86 & & $\mathrm{Ti}$ & 1.50 \\
\hline $\mathrm{MgO}$ & 0.83 & & $\mathrm{Na}$ & $<0.01$ \\
\hline $\mathrm{Na}_{2} \mathrm{O}$ & $<0.01$ & & $\mathrm{~K}$ & $<0.01$ \\
\hline $\mathrm{K}_{2} \mathrm{O}$ & 0.23 & & $\mathrm{Mg}$ & $<0.01$ \\
\hline $\mathrm{CaO}$ & $<0.01$ & $\mathrm{Cr}$ & 0.01 \\
\hline $\mathrm{MnO}$ & 0.25 & $\mathrm{Mn}$ & 0.21 \\
\hline $\mathrm{P}_{2} \mathrm{O}_{3}$ & 0.35 & $\mathrm{P}$ & 0.35 \\
\hline $\mathrm{SO}_{3}$ & 0.33 & $\mathrm{Hg}$ & bdl \\
\hline $\mathrm{Total}_{\mathrm{C}}$ & 2.30 & $\mathrm{~Pb}$ & bdl \\
\hline Total S & 0.28 & $\mathrm{As}$ & bdl \\
\hline Total N & 0.04 & & $\mathrm{Ni}$ & bdl \\
\hline LOI & 11.29 & & $\mathrm{Cd}$ & bdl \\
\hline
\end{tabular}

bdl-below detection limit, LOI-loss on ignition

\section{Solubility of TTM}

An investigation was carried out to assess the stability of TTM under experimental conditions (shaking speed: $200 \mathrm{rpm}$, contact time: $60 \mathrm{~min}$ and $\mathrm{pH}$ : 7). Mineral dissolution was tested via analysis of the concentration of elements in the supernatant solution. The concentrations of the elements in the supernatant solution in wt\% were as follows: Si: 0.034, Fe: 0.01, Al: 0.048, As: < 0.01, Ni: < 0.01, Cd: < 0.01, Cr: 0.048, $\mathrm{Pb}:<0.01$ and $\mathrm{F}:<0.01$. The analysis results indicated that mineral dissolution was insignificant resulting in $<$ $0.1 \mathrm{wt} \%$ of total $\mathrm{Si}, \mathrm{Fe}$ or $\mathrm{Al}$ being dissolved, and the concentrations of elements obtained were significantly lower than the WHO maximum permissible level in drinking water[5]. Therefore, TTM can be used safely as an adsorbent for the removal of fluoride without generating toxic sludge.

\section{Effect of Thermal Treatment}

Investigation of the effect of thermal treatment was carried out using $5 \mathrm{~g} / \mathrm{L}$ raw and calcined (100 to $800^{\circ} \mathrm{C}$ ) termite mound separately in $500 \mathrm{~mL}$ of $10 \mathrm{mg} / \mathrm{L}$ fluoride solution under identical experimental conditions. The results of the effect of calcination temperature on the adsorption of fluoride are shown in Fig. 1 along with the coefficient of distribution and weight loss upon calcination at different temperatures. It was observed that weight loss progressively increased from 4.67 to $27.67 \%$ with the increase in the calcination temperature from 100 to $800^{\circ} \mathrm{C}$. The increase in the loss of weight upon increasing calcinations temperature could be attributed to the loss of considerable structural water molecules (as the moisture and organic matter contents together contributed $6.54 \mathrm{wt} \%$ only) upon increasing calcination temperature [15, 36]. BET and single point surface areas of uncalcined and calcined termite mound are given in Table $\mathbf{2}$. It is obvious that the untreated termite mound had a lower surface area which gradually increased with the increase of calcination temperature up to $600^{\circ} \mathrm{C}$. This increase in surface area with temperature is presumably due to loss of structural water molecules, and formation of $\gamma-\mathrm{Al}_{2} \mathrm{O}_{3}$ and various structural rearrangements which made the material more porous $[15,36]$.

The results (Fig. 1) also revealed that the efficiency of fluoride adsorption and adsorption capacity progressively increased from $\sim 50$ to $\sim 79 \%$ and 0.08 to $0.38 \mathrm{~L} / \mathrm{g}$, respectively with the increase in the heating temperature from 100 to $500^{\circ} \mathrm{C}$. The progressive increase in the percentage of fluoride adsorbed and fluoride binding capacity with the increase of calcination temperature up to $500^{\circ} \mathrm{C}$ could be due to increase in $\mathrm{Al}$, $\mathrm{Ti}$, and Fe content, and increase in the surface area as a result of loss of structural water molecules, and formation of $\gamma$ $\mathrm{Al}_{2} \mathrm{O}_{3}$ which could have a larger surface area $[15,36]$. On the contrary, increasing temperature of calciantion above $500^{\circ} \mathrm{C}$ resulted in the progressive decrease of percent fluoride adsorbed and fluoride adsorption capacity from $\sim 79$ to $\sim 62 \%$ and 0.38 to $0.17 \mathrm{mg} / \mathrm{g}$, respectively. Although the BET surface area of termite mound calcined at $600^{\circ} \mathrm{C}\left(90.75 \mathrm{~m}^{2} / \mathrm{g}\right)$ was higher than that of the $500^{\circ} \mathrm{C}$ calcined $\left(87.81 \mathrm{~m}^{2} / \mathrm{g}\right)$, termite mound calcined $600^{\circ} \mathrm{C}$ demonstrated lower fluoride adsorption efficiency. This could be attributed to a considerable dehydroxylation of oxides which prevail over the effect of increased surface area [15]. The progressive decrease in the adsorption efficiency and binding capacity upon increasing the heating temperature above $500^{\circ} \mathrm{C}$ could be attributed to a significant dehydroxylation of mainly $\mathrm{Al}$ and $\mathrm{Fe}$ oxides, and sintering effect [15]. Similar observations have been observed earlier for different materials $(14,25)$.

The $500^{\circ} \mathrm{C}$ calcined termite mound had higher sorption efficiency $(\sim 79 \%)$ compared to the raw termite mound ( 44\%). Consequently, it can be concluded that TTM could be more effective adsorbent. As a result, further experiments were carried out using TTM for the evaluation of the sorption capacity and optimization of adsorption parameters unless otherwise stated. 


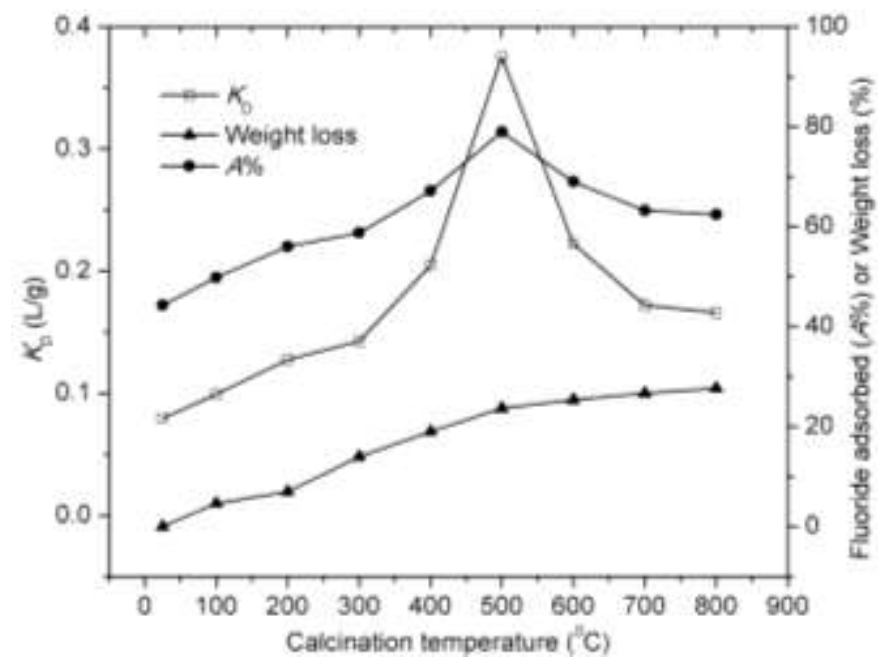

Fig. (1). Effect of heating temperature on weight loss, coefficient of distribution and fluoride adsorption by TTM.

Table 2. Surface Areas of Uncalcined and Calcined Termite Mound

\begin{tabular}{|l|l|l|l|l|l|l|l|l|l|}
\hline Calcination temperature $\left(\mathbf{~}^{\mathbf{0}} \mathbf{C}\right)$ & $\mathbf{2 5}$ & $\mathbf{1 0 0}$ & $\mathbf{2 0 0}$ & $\mathbf{3 0 0}$ & $\mathbf{4 0 0}$ & $\mathbf{5 0 0}$ & $\mathbf{6 0 0}$ & $\mathbf{7 0 0}$ & $\mathbf{8 0 0}$ \\
\hline BET surface area $\left(\mathbf{m}^{\mathbf{2}} / \mathbf{g}\right)$ & 28.40 & $\mathrm{~nm}$ & $\mathrm{~nm}$ & $\mathrm{~nm}$ & 78.36 & 87.81 & 90.75 & $\mathrm{~nm}$ & $\mathrm{~nm}$ \\
\hline Single point surface $\mathbf{a r e a}\left(\mathbf{m}^{\mathbf{2}} / \mathbf{g}\right)$ & 28.34 & $\mathrm{~nm}$ & $\mathrm{~nm}$ & $\mathrm{~nm}$ & 76.07 & 88.20 & 91.13 & $\mathrm{~nm}$ & $\mathrm{~nm}$ \\
\hline
\end{tabular}

nm-not measured

\section{Effect of Contact Time}

To determine the equilibrium time for the adsorption of fluoride, an investigation was conducted using 5,10 and $25 \mathrm{mg} / \mathrm{L}$ fluoride concentrations at solution $\mathrm{pH} \sim 7$ under $12 \mathrm{~g} / \mathrm{L}$ of the adsorbent. The plots of the percentages of fluoride removed versus contact time are given in Fig. 2. Fluoride adsorption was fast within the first $5 \mathrm{~min}$ and afterward very slow until the equilibrium time. The rapid removal of fluoride within the first 5 min of agitation time was due to the presence of competent active binding sites on the surface of TTM at the initial stage of the contact time. Equilibrium was achieved within $30 \mathrm{~min}$ of the agitation time. However, in order to be sure of the attainment of equilibrium, contact time was maintained at $60 \mathrm{~min}$ for further studies. The attainment of the equilibrium time was independent of the initial fluoride concentration 5 to $25 \mathrm{mg} / \mathrm{L}$. Similar results were observed for fluoride removal by activated titanium rich bauxite [15].

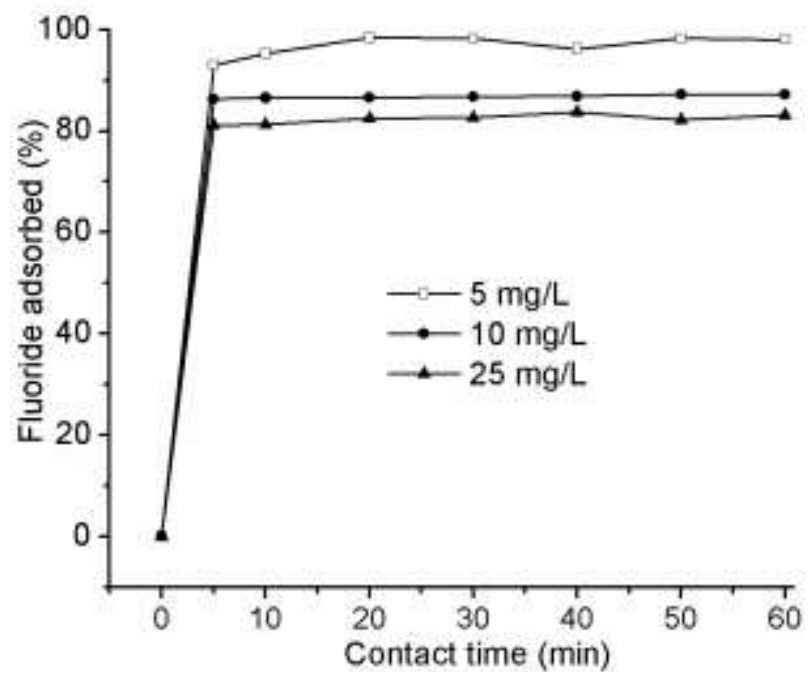

Fig. (2). Effect of contact time on fluoride removal by TTM.

\section{Kinetics Modeling}

The kinetics of fluoride adsorption was studied varying dose of adsorbent (5 to $30 \mathrm{~g} / \mathrm{L}$ and concentration of fluoride ( 5 to $25 \mathrm{mg} / \mathrm{L}$ ) at solution $\mathrm{pH} \sim 7$ keeping the other parameters constant. The adsorption kinetics data followed the pseudo-second-order equation [37] given in Eq. (3): 


$$
\frac{t}{q_{t}}=\frac{1}{q_{e}}(t)+\frac{1}{k_{2} q_{e}^{2}}
$$

where $q_{t}(\mathrm{mg} / \mathrm{g})$ is the amount of fluoride adsorbed per unit mass of TTM at any time $t(\mathrm{~min}), q_{e}(\mathrm{mg} / \mathrm{g})$ is the modeled equilibrium amount of fluoride adsorbed per unit mass of TTM, and $k_{2}(\mathrm{~g} /(\mathrm{mg}$.min) $)$ is the pseudosecond-order rate constant.

The plots of the kinetics of fluoride adsorption are given in Figs. 3 and 4.The pseudo-second-order rate constant $\left(k_{2}\right)$, calculated equilibrium capacity $\left(q_{e, c a l}\right)$ and adsorption affinity $\left(V_{0}=k_{2} q_{\mathrm{e}}{ }^{2}\right)$ were computed from the plots of $t / q_{t}$ versus $t$. The plots of $t / q_{\mathrm{t}}$ versus $t$ were straight lines with correlation coefficients, $R^{2}>0.99$. The calculated pseudo-second-order parameters of fluoride adsorption are given Table 3 . The obtained results show that the values of modeled equilibrium capacities, $q_{e, c a l}$, were remarkably comparable to the experimental equilibrium capacities, $q_{e, e x p}$. Thus, the adsorption of fluoride on TTM could be well described by the pseudosecond-order equation, implying that the rate limiting step may be the chemical adsorption [37]. The values of $k_{2}, q_{\mathrm{e}, \mathrm{cal}}$ and $V_{0}$ obtained from the slope and intercept data of the plots in Fig. 3 showed the increase in $k_{2}$ values (0.818 to $3.938 \mathrm{~g} /(\mathrm{mg} . \mathrm{min})$ ), and the decrease in $q_{\mathrm{e}, \text { cal }}(1.140$ to $0.349 \mathrm{mg} / \mathrm{g})$ and $V_{0}(1.063$ to $0.481 \mathrm{mg} /(\mathrm{g} . \mathrm{min})$ ) values with an increase in the adsorbent dose. Thus, the rate of adsorption increased with an increase in the TTM dose. Whereas, the values of $k_{2}, q_{\mathrm{e}, \mathrm{cal}}$ and $V_{0}$ computed from the slope and intercept data of the plots in Fig. 4 depicted the decrease in $k_{2}$ values (8.749 to $1.568 \mathrm{~g} /(\mathrm{mg} . \mathrm{min})$ ), and the increase in $q_{\mathrm{e}, \text { cal }}(0.477$ to $3.748 \mathrm{mg} / \mathrm{g}$ ) and $V_{0}(1.990$ to $22.026 \mathrm{mg} /(\mathrm{g} . \mathrm{min}))$ values with an increase in the concentration of fluoride. Thus, the rate of adsorption decreased with an increase in the solute concentration, which is similar to the results observed for the removal of fluoride using hydrous iron(III)-tin(IV) bimetal mixed oxide[38].

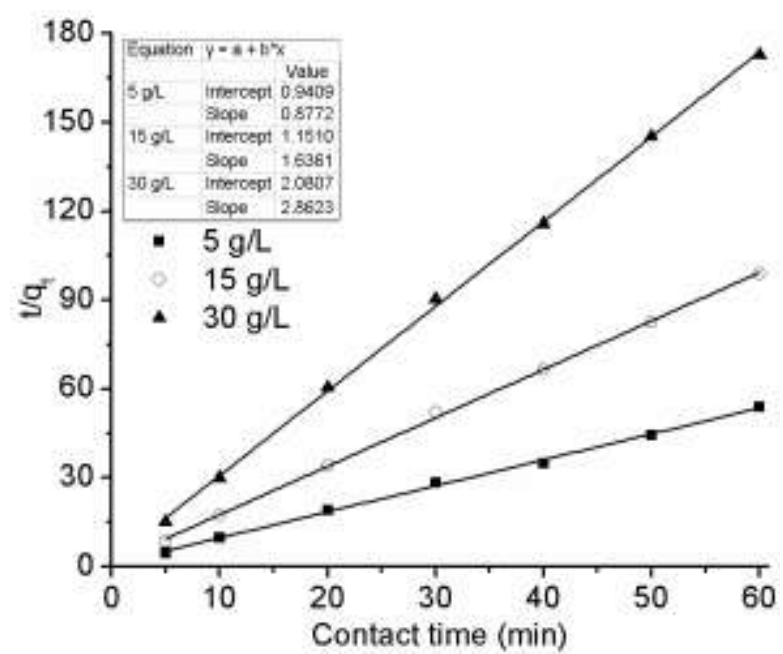

Fig. (3). Pseudo-second order plots related to the effect of adsorbent dose.

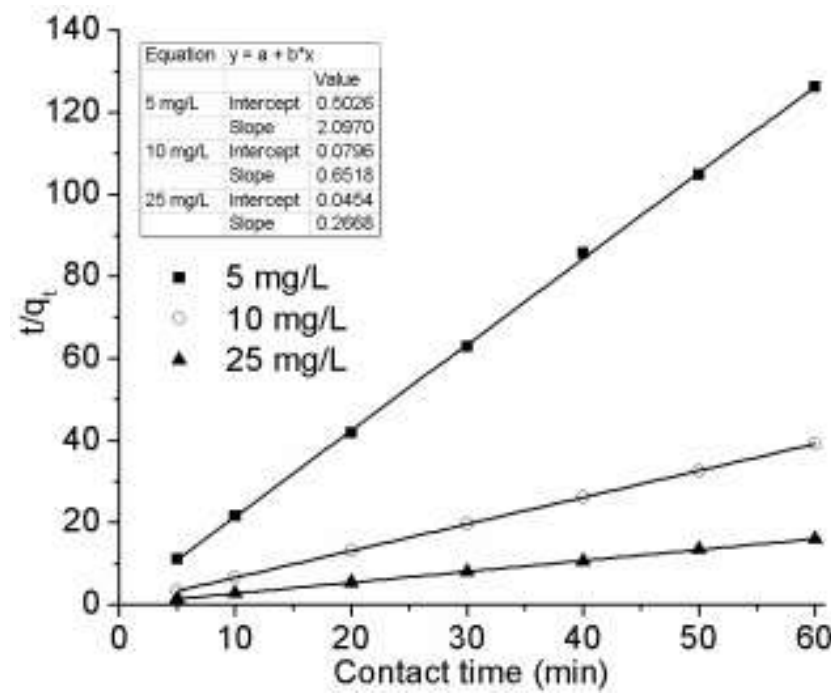

Fig. (4).Pseudo-second order plots related to the effect of initial fluoride concentration.

Table 3. Pseudo-Second-Order Parameters of Adsorption of Fluoride on TTM 
Experimental Evaluation of Activated Termite Mound for Fluoride Adsorption

\begin{tabular}{|c|l|l|l|l|l|l|}
\hline \multirow{2}{*}{ Parameters } & \multicolumn{3}{|c|}{ TTM dose (g/L) } & \multicolumn{3}{c|}{ Fluoride concentration (mg/L) } \\
\cline { 2 - 7 } & 5 & 15 & 30 & 5 & 10 & 25 \\
\hline$q_{e, \exp }(\mathrm{mg} / \mathrm{g})$ & 1.114 & 0.607 & 0.347 & 0.475 & 1.532 & 3.746 \\
\hline$q_{e, c a l}(\mathrm{mg} / \mathrm{g})$ & 1.140 & 0.611 & 0.349 & 0.477 & 1.534 & 3.748 \\
\hline$k_{2}(\mathrm{~g} /(\mathrm{mg} \cdot \mathrm{min}))$ & 0.818 & 2.326 & 3.938 & 8.749 & 5.337 & 1.568 \\
\hline$V_{0}(\mathrm{mg} /(\mathrm{g} \cdot \mathrm{min})$ & 1.063 & 0.869 & 0.481 & 1.990 & 12.563 & 22.026 \\
\hline$R^{2}$ & 0.997 & 0.999 & 0.999 & 0.998 & 0.999 & 0.999 \\
\hline
\end{tabular}

\section{Effect of Solution pH}

The investigation of the effect of $\mathrm{pH}$ on the fluoride adsorption was conducted in between initial solution $\mathrm{pH} \sim 3$ and $\sim 11$ using $10 \mathrm{mg} / \mathrm{L}$ fluoride solution and $12 \mathrm{~g} / \mathrm{L}$ TTM. Graphical presentation of the results is given in Fig. 5. It was observed that the percentage of fluoride adsorption was optimal ( 91\%) in between the initial solution $\mathrm{pH}$ range $\sim 3$ to $\sim 10$, while the percentage significantly decreased from $\sim 90$ to $\sim 45 \%$ with the increase in the solution $\mathrm{pH}$ from $\sim 10$ to $\sim 11$. In the same way, the adsorption capacity was almost constant $(\sim$ $0.765 \mathrm{mg} / \mathrm{g}$ ) in the $\mathrm{pH}$ range $\sim 3$ to $\sim 10$.The high percentage of fluoride removal in the range of $\mathrm{pH} \sim 3$ to $\sim 10$ could be attributed to the amphoteric nature of $\mathrm{Al}$ and $\mathrm{Fe}$ oxides content of the adsorbent [39-42]. The $\mathrm{pH}$ dependency of fluoride removal can also be explained considering the $\mathrm{pH}_{\mathrm{PZC}}$ of the adsorbent. The $\mathrm{pH}_{\mathrm{PZC}}$ of termite mound used in the present study determined by the potentiometric titration method was found to be 7.96. The observed value of $\mathrm{pH}_{\mathrm{PZC}}$ is within the range of the $\mathrm{pH}_{\mathrm{PZC}}, 5.5$ to 8.3 , of the mixture of oxides of $\mathrm{Si}, \mathrm{Fe}, \mathrm{Al}$, and $\mathrm{Ti}[34]$ and is also comparable to the $\mathrm{pH}_{\mathrm{PZC}}$ determined for the termite mound $\left(\mathrm{pH}_{\mathrm{PZC}}=7.8\right)$ evaluated for the removal of $\mathrm{Pb}$ (II) [35]. Consequently, when the $\mathrm{pH}<\mathrm{pH}_{\mathrm{pzc}}$, the columbic attraction would be responsible for the adsorption of fluoride ions onto the surface of adsorbent (Eq. (4)), and when the $\mathrm{pH}>\mathrm{pH}_{\mathrm{pzc}}$, the fluoride ions would be adsorbed through a ligand exchange process (Eqs. (5) and (6)) [43].

$$
\begin{aligned}
& \equiv \mathrm{MOH}_{2}^{+}+\mathrm{F}^{-} \leftrightarrow \equiv \mathrm{MOH}_{2}^{+} \cdots \mathrm{F}^{-} \\
& \equiv \mathrm{MOH}+\mathrm{F}^{-} \leftrightarrow \equiv \mathrm{MF}+\mathrm{OH}^{-} \\
& \equiv \mathrm{MOH}_{2}^{+}+\mathrm{F}^{-} \leftrightarrow \equiv \mathrm{MF}+\mathrm{H}_{2} \mathrm{O}
\end{aligned}
$$

where $\mathrm{M}$ represents $\mathrm{Si}, \mathrm{Al}, \mathrm{Fe}$ and $\mathrm{Ti}$ etc. Importantly, the high percentage of fluoride removal in the basic medium up to $\mathrm{pH} \sim 10$ is of a great interest in the practical application. The decrease in the percentage of fluoride adsorbed at $\mathrm{pH}>10$ could be due to the competition of hydroxyl ions or electrostatic repulsion of fluoride ion by the negatively charged surface [44]. The slight fluctuation of adsorption of fluoride in the $\mathrm{pH}$ range from $\sim 3$ to $\sim 10$ may be due to both specific and nonspecific adsorptions of fluoride on the adsorbent [44].

Furthermore, when the initial solution $\mathrm{pH}$ was in the range of $\sim 4$ to $\sim 10$, the $\mathrm{pH}$ values after adsorption were $\sim 6.64$ (data not shown). This implies that TTM had the capacity of maintaining a neutral pH after adsorption. The capacity of maintaining a neutral solution $\mathrm{pH}$ may result from the amphoteric nature of oxides of $\mathrm{Al}$ and $\mathrm{Fe}[39,40]$, and the negligible compositional content of basic ionic metallic oxides of termite mound (Table 1). Consequently, the effect of the basic metallic oxides to increase the $\mathrm{pH}$ of the solution was negligible and overshadowed by the effect of the oxides of $\mathrm{Al}$ and Fe. The result is similar to previous defluoridation studies $[13,45,46]$.

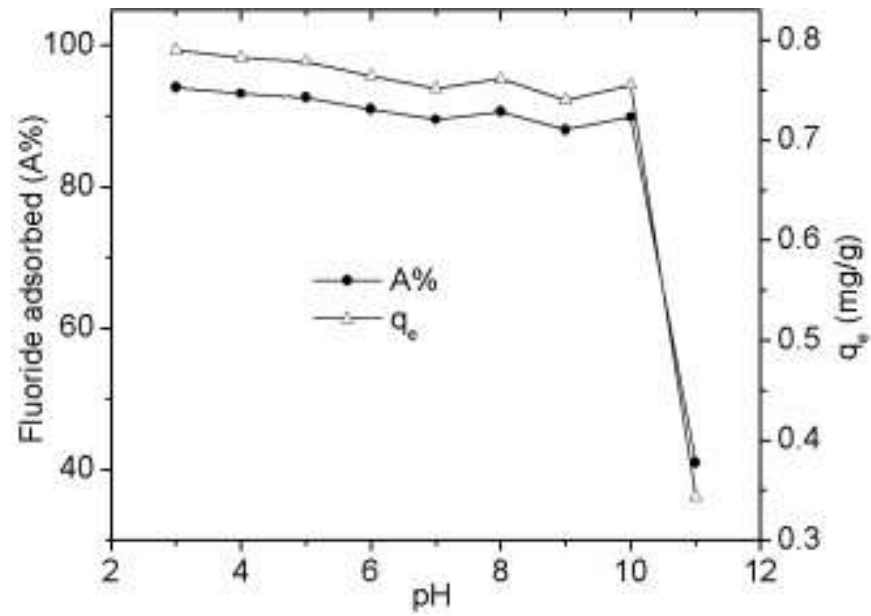

Fig. (5).Effect of $\mathrm{pH}$ on fluoride removal by TTM.

\section{Adsorbent Dose}

To determine the required minimum dose for maximum fluoride adsorption, an experiment was conducted varying the amount of TTM from 5 to $28 \mathrm{~g} / \mathrm{L}$. The plots of the percentage of fluoride adsorbed and loading capacity versus adsorbent dose are given in Fig. 6. Fluoride loading capacity (amount of fluoride loaded 
per unit weight of adsorbent) decreased from $\sim 1.76$ to $\sim 0.39 \mathrm{mg} / \mathrm{g}$ with the increase in the dose from 5 to 28 $\mathrm{g} / \mathrm{L}$. This decrease in the amount adsorbed could be due to the decrease in the fluoride/active binding sites ratio [20]. In contrast, with increase in the dose of the adsorbent from 5 to $28 \mathrm{~g} / \mathrm{L}$ percent fluoride removal increased from $\sim 79$ to $\sim 99 \%$. This increase in the percentage of removal can be attributed to the availability of more adsorption sites at a higher adsorbent dose [20, 47]. In the present study, the permissible limit of fluoride in drinking water according to WHO, $1.5 \mathrm{mg} / \mathrm{L}$, was attained at TTM dose of $12 \mathrm{~g} / \mathrm{L}$, which reduced $10 \mathrm{mg} / \mathrm{L}$ fluoride to $1.37 \mathrm{mg} / \mathrm{L}$. Hence, $12 \mathrm{~g} / \mathrm{L}$ TTM was considered as the optimal dose for further studies unless otherwise stated.

The coefficient of distribution, $K_{D}(\mathrm{~L} / \mathrm{g})$, which shows the binding ability of adsorbent surface, was computed using $K_{\mathrm{D}}=q_{\mathrm{e}} / C_{\mathrm{e}}$ [48], where $q_{\mathrm{e}}$ and $C_{\mathrm{e}}$ are described elsewhere. The value of $K_{D}$ increased from 0.74 to $2.92 \mathrm{~L} / \mathrm{g}$ as a function of the adsorbent amount at $\mathrm{pH} \sim 7$ (plot not shown). The increase in $K_{\mathrm{D}}$ value at a given $\mathrm{pH}$ indicates the heterogeneity of the surface of the adsorbent [48].

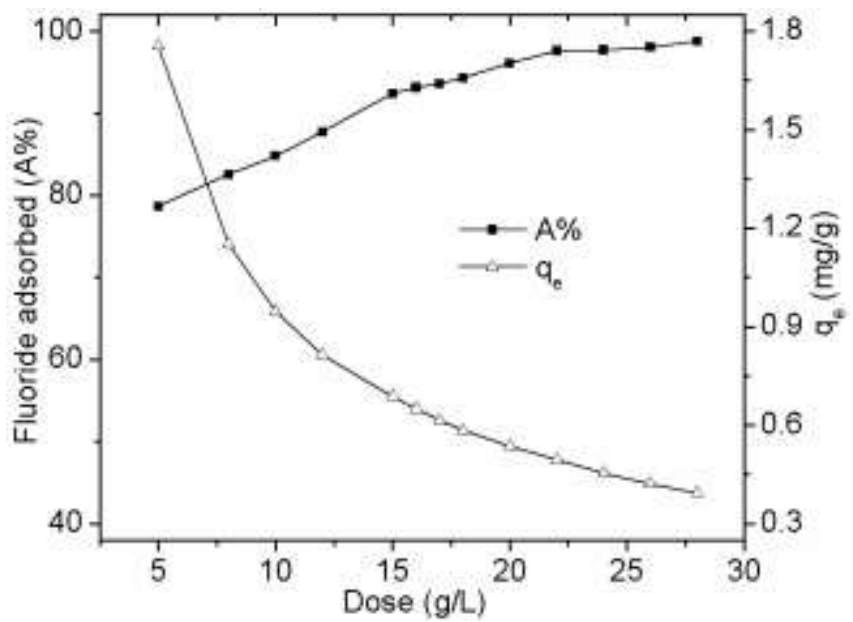

Fig. (6). Effect of adsorbent dose on adsorption of fluoride by TTM.

\section{Effect of Initial Fluoride Concentration}

The effect of varying the level of concentration of fluoride from 3 to $155 \mathrm{mg} / \mathrm{L}$ on the adsorption of fluoride was assessed at solution $\mathrm{pH} \sim 7$ using $12 \mathrm{~g} / \mathrm{L}$ TTM. The plots of the amount of fluoride removed and percentage of fluoride adsorbed against the initial concentration of fluoride are given in Fig. 7. It was observed that the fluoride adsorption capacity gradually increased from $\sim 0.19$ to $\sim 5.53 \mathrm{mg} / \mathrm{g}$ with the increase in the concentration of fluoride from 3 to $155 \mathrm{mg} / \mathrm{L}$, which could be attributed to the availability of more fluoride ions for adsorption at higher concentration [49]. In contrast, the percentage of fluoride removal showed a progressive decreasing trend from $\sim 98$ to $\sim 43 \%$ with the increase in the concentration of fluoride from 3 to $155 \mathrm{mg} / \mathrm{L}$. Most fluoride ions adsorbed to the binding sites at low initial concentration, resulting in a high percentage of fluoride adsorbed, while only part of the fluoride combined with the limited binding sites at high initial concentration, resulting in a relatively low removal percentage [42]. Similar observations have been made earlier [46, 47].

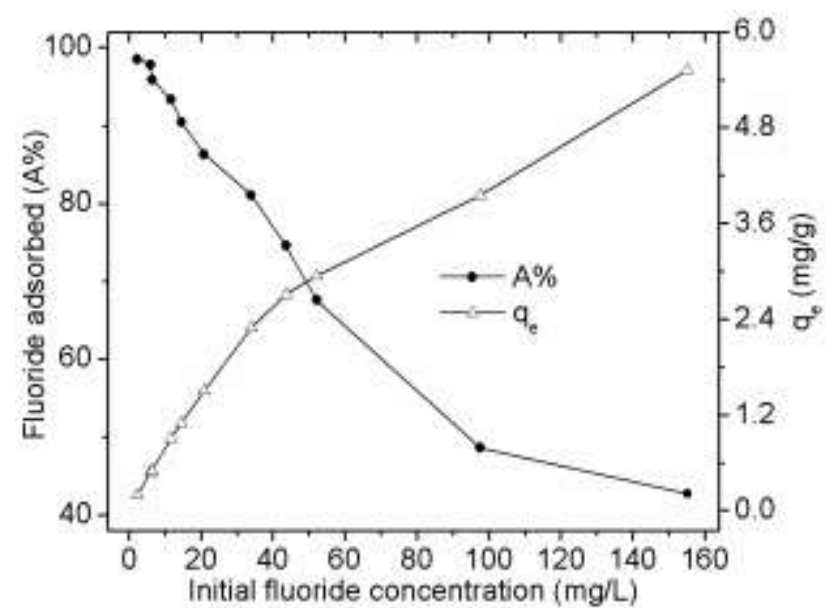

Fig. (7). Effect of initial fluoride concentration on fluoride removal by TTM.

Analysis of Equilibrium Isotherm Data 
Nonlinear forms [48, 50-52] of the Langmuir (Eq. (7)), Freundlich (Eq. (8)) and Dubinin-Radushkevich (D-R) (Eq. (9)) were applied to analyze the fluoride adsorption capacity of TTM at equilibrium, and the mathematical equations of the isotherm models are given below:

$$
\begin{aligned}
& q_{e}=\frac{Q_{\max } b C_{e}}{1+b C_{e}} \\
& q_{e}=K_{F} C_{e}^{1 / n} \\
& q_{e}=q_{m} \exp \left(-K_{D R} \varepsilon^{2}\right) \\
& \varepsilon=R T \ln \left(1+\frac{1}{C_{e}}\right)
\end{aligned}
$$

where $C_{e}(\mathrm{mg} / \mathrm{L})$ is the concentration of fluoride in the aqueous phase at equilibrium, $q_{e}(\mathrm{mg} / \mathrm{g})$ is the amount of fluoride adsorbed at equilibrium per unit mass of TTM, $Q_{\max }(\mathrm{mg} / \mathrm{g})$ is the adsorption capacity based on the Langmuir equation, and $b(\mathrm{~L} / \mathrm{mg})$ is the Langmuir constant, $K_{F}\left[\left(\mathrm{mg}^{1-1 / n} \mathrm{~L}^{1 / \mathrm{n}}\right) / \mathrm{g}\right]$ is Fredundlich coefficient ofadsorption, $1 / n$ is the adsorption intensity based on the Freundlich equation, $q_{m}\left(\mathrm{~mol} \mathrm{~g}^{-1}\right)$ is the molar adsorption capacity based on the D-Requation, $K_{D R}\left(\mathrm{~mol}^{2} / \mathrm{kJ}^{2}\right)$ is the activity coefficient related to the mean sorption energy, $\varepsilon\left(\mathrm{mol}^{2} / \mathrm{kJ}^{2}\right)$ is the Polanyi potential, $R(\mathrm{~kJ} /(\mathrm{mol} . \mathrm{K}))$ is the gas constant, and $T(\mathrm{~K})$ isthe temperature of the equilibrium experiment.

The chi-squared test, $\chi^{2}$, which is given by Eq. (11), was carried out to identify the most suitable isotherm model that well describes the sorption system, and the less the difference between the experimental and modeled equilibrium capacities, the less the value of $\chi^{2}[53]$.

$$
\chi^{2}=\sum \frac{\left(q_{e}-q_{e, c a l}\right)^{2}}{q_{e, c a l}}
$$

(11)

where $q_{\mathrm{e}, c a l}(\mathrm{mg} / \mathrm{g})$ is the equilibrium capacity obtained by calculating from the model and $q_{\mathrm{e}}(\mathrm{mg} / \mathrm{g})$ is the experimental data on the equilibrium capacity.

The plots of the equilibrium adsorption isotherms of fluoride on TTM are given in Fig. 8. Values of the equilibrium constants obtained from their respective nonlinear forms of the isotherm are given in Table 4. The Freundlich and D-R isotherms demonstrated higher values of determination coefficients, $R^{2}>0.98$, and lower values of chi-square, $\chi^{2} \sim 0.20$. Thus, both isotherm models more satisfactorily described the equilibrium data of fluoride adsorption on TTM.

The essential characteristic of the Langmuir isotherm is expressed in terms of a dimensionless constant separation factor, $R_{\mathrm{L}}$, which describes the type of isotherm [54], and was computed by $R_{\mathrm{L}}=1+\left(1 / b C_{0}\right)$ where, $C_{0}$ $(\mathrm{mg} / \mathrm{L})$ is the initial concentration of fluoride. The values of $R_{\mathrm{L}}$ calculated were 0.06 to 0.79 that are between 0 and 1.0, suggesting favorableadsorption of fluoride on TTM. The nature of adsorption isotherm can also be suggested by the magnitude of adsorption intensity of the Freundlich constant, $n$. The value of $n$ for fluoride removal by TTM was found to be 2.74 that is between 1.0 and 10.0, indicating a favorable adsorption system[15]. A similar observation was made by Solangi et al. [51].

The D-R equation is used to compute the mean free energy of sorption and assumes the heterogeneity of energies over the binding surface of adsorbent [51]. The mean sorption energy, $E_{D R}(\mathrm{~kJ} / \mathrm{mol})$, was computed from D-R isotherm using the equation $E_{\mathrm{DR}}=\left(-2 K_{D R}\right)^{-0.5}[55]$. The magnitude of $E_{D R}$ is useful to evaluate the nature of interaction between fluoride ion and the binding sites. The calculated value of $E_{D R}$ for fluoride adsorption on TTM was $11.12 \mathrm{~kJ} / \mathrm{mol}$ that is within the energy range of chemical sorption reactions, 8.0 to 16.0 $\mathrm{kJ} / \mathrm{mol}$ [54]. Thus, the adsorption of fluoride onTTM took place mainly through the chemical sorption process. 


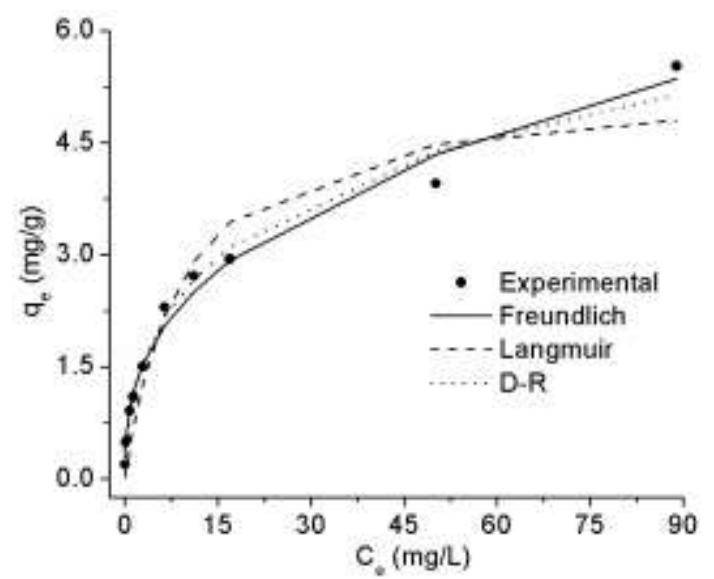

Fig. (8). Isotherm models of fluoride sorption TTM.

Table 4.Isotherm parameters of equilibrium adsorption of fluoride on TTM

\begin{tabular}{|c|l|l|l|l|l|}
\hline \multicolumn{2}{|c|}{ Freundlich } & \multicolumn{2}{c|}{ Langmuir } & \multicolumn{2}{c|}{ Dubinin-Radushkevich } \\
\hline$K_{F}\left[\left(\mathrm{mg}^{1-1 / n} \mathrm{~L}^{1 / \mathrm{n}}\right) / \mathrm{g}\right]$ & 1.04 & $Q_{\max }(\mathrm{mg} / \mathrm{g})$ & 5.29 & $K_{\mathrm{DR}}(\mathrm{mg} / \mathrm{g})$ & 10.49 \\
\hline$n$ & 2.74 & $b(\mathrm{~L} / \mathrm{mg})$ & 0.11 & $E_{D R}(\mathrm{~kJ} / \mathrm{mol})$ & 11.12 \\
\hline$R^{2}$ & 0.989 & $R_{\mathrm{L}}$ & $0.06-0.79$ & $R^{2}$ & 0.985 \\
\hline$\chi^{2}$ & 0.163 & $R^{2}$ & 0.953 & $\chi^{2}$ & 0.203 \\
\hline & & $\chi^{2}$ & 5.751 & & \\
\hline
\end{tabular}

\section{Effect of Co-existing Anions}

The effects of the presence of co-existing anions in the solution on the efficiency of fluoride removal by TTM were investigated at solution $\mathrm{pH} \sim 7$ varying the concentration of the anions from 10 to $500 \mathrm{mg} / \mathrm{L}$ under $10 \mathrm{mg} / \mathrm{L}$ fluoride and $12 \mathrm{~g} / \mathrm{L}$ TTM. Graphical presentation of the efficiency of fluoride removal as a function of the concentration of co-existing anions is given in Fig. 9. The result showed that the adsorption efficiency was significantly decreased in the presence of $\mathrm{PO}_{4}{ }^{3-}$ and $\mathrm{CO}_{3}{ }^{2-}$ ions in the solution at a higher concentration range of 100 to $500 \mathrm{mg} / \mathrm{L}$. This presumably attributed to the high affinity and capacity of TTM for $\mathrm{PO}_{4}{ }^{3-}$ and $\mathrm{CO}_{3}{ }^{2-}$ ions [18]. A similar observation has been made by Chen et al [56]. Fortunately, carbonate and phosphate ions are absent or very little in most groundwater sources of the Main Ethiopian Rift [3, 4]. The results also revealed that the adsorption of fluoride was greatly affected in the presence of the mixture of the anions in the solution in the concentration range of 100 to $500 \mathrm{mg} / \mathrm{L}$, indicating that the effect of $\mathrm{PO}_{4}{ }^{3-}$ and $\mathrm{CO}_{3}{ }^{2-}$ ions overshadowed the influence of the presence of the other anions. The presence of $\mathrm{HCO}_{3}$ ion in the concentration range of 100 to 500 $\mathrm{mg} / \mathrm{L}$ slightly decreased the adsorption efficiency. A similar observation of the effect of $\mathrm{HCO}_{3}{ }^{-}$onthe efficiency of fluoride adsorption has been investigated using chemical treated laterite [14].

In contrast, with the increase in the concentration of $\mathrm{Cl}^{-}, \mathrm{SO}_{4}{ }^{2-}$ and $\mathrm{NO}_{3}{ }^{-}$ions in the solution the percentage of fluoride adsorbed slightly increased suggesting the inner sphere complexation between the fluoride ions and the active binding sites of TTM[14]. Similar results were observed by Meenakish et al. [53]. In general, the results of the effects of co-existing anions on the efficiency of fluoride adsorption on TTM are similar to the observation made by Chen et al. [56] for the removal of fluoride by porous granular ceramic.

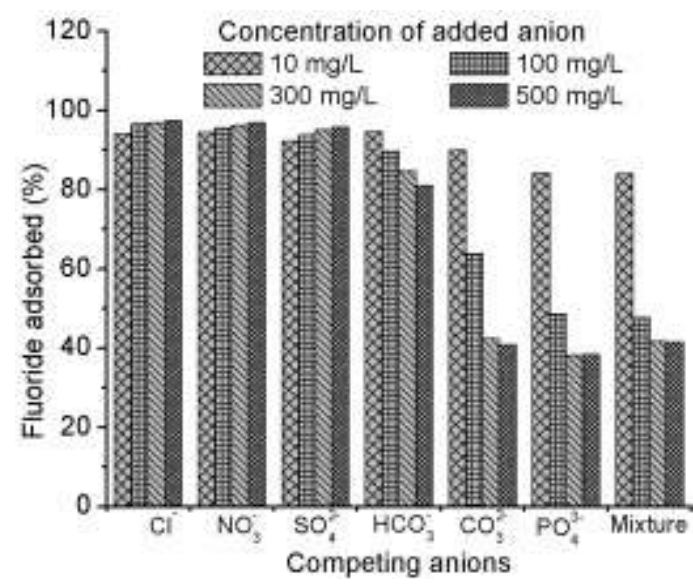

Fig. (9). Effect of co-existing anions on the removal of fluoride by TTM. 


\section{Defluoridation of Natural Groundwater}

Two groundwater samples containing 7.56 and $15.93 \mathrm{mg} / \mathrm{L}$ fluoride from two wells were collected from the Main Campus of Jimma University, Oromia Regional National State, Ethiopia. The physico-chemical characteristics of the samples are reported in Table 5. The fluoride contaminated water samples were defluoridated using $12 \mathrm{~g} / \mathrm{L}$ TTM without adjusting the $\mathrm{pHs}$ of the samples. Accordingly, the $15.95 \mathrm{mg} / \mathrm{L}$ fluoride concentration of Well 1 was reduced to $2.92 \mathrm{mg} / \mathrm{L}$, which is below the fluoride level in drinking water suggested by the Ministry of Water Resources of Ethiopia, $3 \mathrm{mg} / \mathrm{L}$. However, the reduction of $15.95 \mathrm{mg} / \mathrm{L}$ fluoride concentration to $2.92 \mathrm{mg} / \mathrm{L}$ signified the need for a successive treatment to reduce the fluoride level to the WHO permissible level, $1.5 \mathrm{mg} / \mathrm{L}$. On the other hand, the $7.56 \mathrm{mg} / \mathrm{L}$ fluoride content of Well 2 was successfully reduced to $1.06 \mathrm{mg} / \mathrm{L}$, which is below the acceptable value of $1.5 \mathrm{mg} / \mathrm{L}$. Thus TTM could be successfully applied for the treatment of natural groundwater containing excess fluoride.

Table 5. Physico-chemical Characteristics of Groundwater Samples

\begin{tabular}{|l|l|l|}
\hline Characteristic parameter & Well 1 & Well 2 \\
\hline Conductivity $\left(\mu \mathrm{S} \mathrm{cm}^{-1}\right)$ & 1217.00 & 1215.00 \\
\hline Total hardness $\left(\mathrm{mg} \mathrm{L}^{-1}\right)$ as $\mathrm{CaCO}_{3}$ & 645.56 & 738.00 \\
\hline Carbonate $\left(\mathrm{mg} \mathrm{L}^{-1}\right)$ as $\mathrm{CO}_{3}^{2-}$ & Nil & Nil \\
\hline Bicarbonate $\left(\mathrm{mg} \mathrm{L}^{-1}\right)$ as $\mathrm{HCO}_{3}^{-}$ & 623.45 & 764.94 \\
\hline Chloride $\left(\mathrm{mg} \mathrm{L}^{-1}\right)$ as Cl & 12.04 & 3.41 \\
\hline Nitrate $\left(\mathrm{mg} \mathrm{L}^{-1}\right)$ as NO${ }^{-}$ & 17.12 & 0.20 \\
\hline Sulfate $\left(\mathrm{mg} \mathrm{L}^{-1}\right)$ as $\mathrm{SO}_{4}^{2-}$ & 1.22 & 3.94 \\
\hline Phosphate $\left(\mathrm{mg} \mathrm{L}^{-1}\right) \mathrm{as} \mathrm{PO}_{4}{ }^{3-}$ & Nil & 0.12 \\
\hline Fluoride $\left(\mathrm{mg} \mathrm{L}^{-1}\right)$ as F & 15.93 & 7.56 \\
\hline Calcium $\left(\mathrm{mg} \mathrm{L}^{-1}\right)$ as Ca & 24.00 & 10.64 \\
\hline Magnesium $\left(\mathrm{mg}^{2-1}\right) \mathrm{as} \mathrm{Mg}^{2+}$ & 7.89 & 3.65 \\
\hline Sodium $\left(\mathrm{mg} \mathrm{L}^{-1}\right)$ as Na & 289.12 & 278.00 \\
\hline $\mathrm{pH}$ & 7.94 & 7.87 \\
\hline
\end{tabular}

\section{Adsorption Efficiency of Regenerated TTM}

The reusability of an adsorbent is mainly based on the ease with which an adsorbate is released from the spent adsorbent and the adsorption efficiency of the regenerated spent adsorbent. The effect of $\mathrm{pH}$ on fluoride removal by TTM showed (Fig. 5) that fluoride adsorption capacity was very low at $\mathrm{pH}>10$, suggesting the possibility of desorbing adsorbed fluoride from the spent adsorbent using alkaline solution of $\mathrm{pH}>10$. Based on this, batch desorption of $\sim 87 \%$ fluoride adsorbed was carried out under identical experimental conditions of the batch sorption studies (subsection 2.4) using $500 \mathrm{~mL}$ of CES, $0.1 \mathrm{M}$ and $0.2 \mathrm{M} \mathrm{NaOH}$ solution, separately. The percentages of fluoride desorbed at $\mathrm{pH}>12$ using CES, 0.1 M and $0.2 \mathrm{M} \mathrm{NaOH}$ solutions were 66.75, 80.64 and $96.60 \%$, respectively (Fig. 10). Consequently, fluoride loaded TTM could be successfully regenerated using $\mathrm{NaOH}$ solution. The mechanism of fluoride desorption from the exhaustedTTM can be interpreted in terms of the ligand exchange mechanism as depicted in Eq. (12).

$\equiv \mathrm{MF}+\mathrm{OH}^{-} \leftrightarrow \equiv \mathrm{MOH}+\mathrm{F}^{-}$

Figure10 shows that adsorption efficiency of $89.79,92.09$ and $97.43 \%$ were achieved respectively with CES, 0.1 and $0.2 \mathrm{M} \mathrm{NaOH}$ solutions regenerated and rinsed with $0.1 \mathrm{M} \mathrm{HCl}$ spent TTM. The performances of fluoride loaded TTM regenerated using CES, $0.1 \mathrm{M}$ and $0.2 \mathrm{M} \mathrm{NaOH}$ solution were found to be superior to that of the fresh TTM. Thus, the regenerated adsorbent rinsed with $0.1 \mathrm{M} \mathrm{HCl}$ was more efficient than the fresh TTM that could be due to the effect of $\mathrm{HCl}$ that could make the adsorbent more porous. It is important to notice that the spent TM regenerated by any of the desorbent solution was competent to reduce $10 \mathrm{mg} / \mathrm{L}$ fluoride to below $1.5 \mathrm{mg} / \mathrm{L}$, the maximum allowed fluoride concentration in drinking water.

The loss of Fe and $\mathrm{Al}$ from TTM during desorption was investigated by analyzing their respective concentrations in the supernatant solution after shaking the adsorbent at $200 \mathrm{rpm}$ for $60 \mathrm{~min}$ at $\mathrm{pH} 12.81$. It was found that $0.01 \% \mathrm{Fe}$ and $0.70 \% \mathrm{Al}$, which is together $<1 \%$, were released from the adsorbent, indicating that TTM was stable under regeneration conditions. It was also observed that of $\sim 87 \%$ fluoride adsorbed, only $3.67 \%$ fluoride was released from fluoride loadedTTM at $\mathrm{pH} \sim 5.0$. The results of adsorption-desorptionadsoption cycle showed that fluoride loaded TM can be regenerated using CES or NaOH solution for effective reuse with insignificant loss of metals, or spent TTM could be safely disposed at $\mathrm{pH} \leq 5.0$. However, further investigation will be required to determine the exact life cycle of the regenerated TM. 


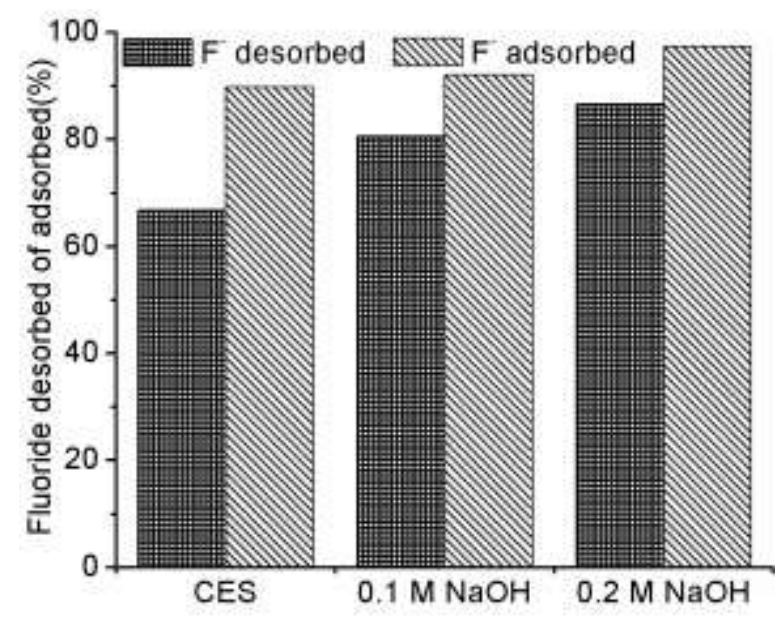

Fig. (10) Fluoride desorbed and adsorbed during an adsorption-desorption-adsorption cycle.

\section{Conclusions}

The present study showed that the fluoride adsorption capacity of termite mound, containing mainly $\mathrm{Al}, \mathrm{Fe}, \mathrm{Ti}$ and $\mathrm{Si}$ oxides could be enhanced by thermally activation. Although the adsorption of fluoride is dependent on contact time, adsorbent dose, solution $\mathrm{pH}$, interfering anions, and concentration of fluoride, the presence of carbonate and phosphate ions at high concentration levels remains the most important factor. The fluoride adsorption efficiency is high over the $\mathrm{pH}$ of the natural groundwater overcoming the need for $\mathrm{pH}$ adjustment. The fitting of pseudo-second order rate equation to the adsorption kinetics data and the computed value of sorption energy signify the dominance of chemisorption mechanism in the removal fluoride.TTM could be effectively applied for the defluoridation of moderately contaminated groundwater. Successful desorption of fluoride from loaded TTMand high adsorption efficiency of the regenerated spent adsorbent signify the stability and suitability of TTM for defluoridation. In general, the results of this study provides valuable data of the process of fluoride adsorption on TTMwarranting further investigations for the practical applicability of the adsorbent to develop household defluoridation technique.

\section{Acknowledgements}

The author is thankful to the University of Rostockfor permitting me the Soil Physics Laboratory for the characterizing the adsorbent. The help from Mr. Reinhard Eckelt of Leibniz-Istitut für Katalyse der Unversität Rostock e.v in determining the specific surface area and chemical compositions of the adsorbent is immense.Finally, I would like to thank the laboratory technicians at Biology Department, Jimma University for allowing me to use the analytical instrument.

\section{References}

[1] Maliyekkal SM, Shukla S, Philip L, Nambi IM. Enhanced fluoride removal from drinking water by magnesia-amended activated alumina granules. Chem Eng J 2008;183-192.

[2] Mohapatra M, Anand S, Mishra BK, Giles DE, Singh P. Review of fluoride removal from drinking water. J Environ Manage 2009;67-77.

[3] Furi W, Razack M, Abiye TA, Ayenew T, Legesse D. Fluoride enrichment mechanism and geospatial distribution in the volcanic aquifers of the Middle Awash basin, Northern Main Ethiopian Rift. J Afr Earth Sci 2011;315-327.

[4] Rango T, Bianchini G, Beccaluva L, Tassinari R. Geochemistry and water quality assessment of central Main Ethiopian Rift natural waters with emphasis on source and occurrence of fluoride and arsenic. J Afr Earth Sci 2010;479-491.

[5] WHO. Guidelines for drinking water quality, First Addendum to $3^{\text {rd }}$ ed. Vol. 1: Recomendations. World Health Organization, Geneve, Switzerland 2006.

[6] Federal Democratic Republic of Ethiopia. Ethiopian quality and standard authority Guidelines for drinking water quality, Addis Ababa 2001.

[7] Federal Democratic Republic of Ethiopia MoWR. Ethiopia Guidelines Specification for Drinking Water Quality, Addis Ababa 2002.

[8] Sehn P. Fluoride removal with extra low energy reverse osmosis membranes: Three years of large scale field experience in Finland. Desalination 2008;73-84.

[9] Lahnid S, Tahaikt M, Elaroui K, Idrissi I, Hafsi M, Laaziz I, Amor Z, Tiyal F, Elmidaoui A. Economic evaluation of fluoride removal by electrodialysis. Desalination 2008;213-219.

[10] Kir E, Alkan E. Fluoride removal by Donnan dialysis with plasma-modified and unmodified anion-exchange membranes. Desalination 2006;217-224.

[11] Elazhar F, Tahaikt M, Achatei A, Elmidaoui F, Taky M, El Hannouni F, Laaziz I, Jariri S, El Amrani M, Elmidaoui A. Economical evaluation of the fluoride removal by nanofiltration. Desalination 2009;154-157.

[12] Alkan E, Kir E, Oksuz L. Plasma modification of the anion-exchange membrane and its influence on fluoride removal from water. Sep Purif Techn 2008;455-460.

[13] Nigussie W, Zewge F, Chandravanshi BS. Removal of excess fluoride from water using waste residue from alum manufacturing process. J Hazard Mater 2007;954-963. 
[14] Maiti A, Basu JK, De S. Chemical treated laterite as promising fluoride adsorbent for aqueous system and kinetic modeling. Desalination 201;28-36.

[15] Das N, Pattanaik P, Das R. Defluoridation of drinking water using activated titanium rich bauxite. J Colloid Interface Sci 2005;1-10.

[16] [16] Kaufhold S, Dohrmann R, Abidin Z, Henmi T, Matsue N, Eichinger L, Kaufhold A, Jahn R. Allophane compared with other sorbent minerals for the removal of fluoride from water with particular focus on a mineable Ecuadorian allophane. Appl Clay Sci 2010;25-33.

[17] Leyva-Ramos R, Rivera-Utrilla J, Medellin-Castillo NA, Sanchez-Polo M. Kinetic modeling of fluoride adsorption from aqueous solution onto bone char. Chem Eng J 2010;458-467.

[18] Chen N, Zhang Z, Feng C, Li M, Zhu D, Chen R, Sugiura N. An excellent fluoride sorption behavior of ceramic adsorbent. J Hazard Mater 2010;460-465.

[19] Masamba WRL, Sajidu SM, Thole B, Mwatseteza JF. Water defluoridation using Malawi's locally sourced gypsum. Phys Chem Earth 2005;846-849.

[20] Thole B. Defluoridation kinetics of $200^{\circ} \mathrm{C}$ calcined bauxite, gypsum, and magnesite and breakthrough characteristics of their composite filter. J Fluor Chem 2011;529-535.

[21] Huang Y-H, Shih Y-J, Chang C-C. Adsorption of fluoride by waste iron oxide: The effects of solution pH, major coexisting anions, and adsorbent calcination temperature. J Hazard Mater 2011;1355-1359.

[22] OADB. Phase II: Integrated pilot project for termite control in 8 districts of East and West Wellega Zone, Oromia. Agricultural Development Bureau, March 20, Finfinnee, Ethiopia. 2001.

[23] Tilahun A, Kebede F, Yamoah C, Erens H, Mujinya BB, Verdoodt A, Van Ranst E. Quantifying the masses of Macrotermes subhyalinus mounds and evaluating their use as a soil amendment. Agri Ecosyst Environ 2012;54- 59.

[24] Abdulrahman A. Foraging activity and control of termites in western Ethiopia, PhD thesis, University of London, London. 1990:277-278.

[25] Liu C, Evett JB. Soil properties-testing, measurment, and evaluation. ISBN 0-13-093005-9, Banta Book Company, USA. 2003.

[26] Appel C, Ma, L.Q.,. Concentration, pH, and surface charge effects on Cd and Pb sorption in three tropical soils. J Environ Qual 2002;581-589. .

[27] Chip Appel, Lena Q. Ma, R. Dean Rhue, Elizabeth Kennelle. Point of zero charge determination in soils and minerals via traditional methods and detection of electroacoustic mobility. Geoderma 2003;77-97.

[28] DIN ISO 10694 . Bodenbeschaffenheit-Bestimmung von organischem Kohlenstoff und Gesamtkohlenstoff nach trockener Verbrennung (Elementaranalyse). Beuth Verlag, Berlin. 1996.

[29] DIN ISO 13878. Bodenbeschaffenheit - Bestimmung des Gesamt-Stickstoffs durch trockene Verbrennung (Elementaranalyse). Beuth, Berlin, Vienna, Zurich 1998.

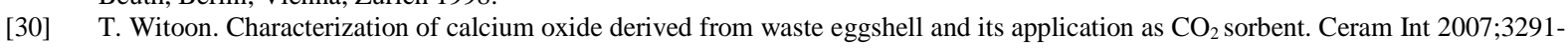
3298 .

[31] G. Gergely, F. Wéber, I. Lukács, A. L. Tóth, Z. E. Horváth, J. Mihály, Balázsi C. Preparation and characterization of hydroxyapatite from eggshell. Ceram Int 2010;803-806.

[32] C. Balázas, Z. Kövér, E. Hörváth, C. Néméth, Z. Kasztovszky, S. Kurunczi, F. Wéber. Examination of calcium-phosphates prepared from eggshell. Mater Sci Forum 2007;105-112.

[33] Sun Y, Fang Q, Dong J, Cheng X, Xu J. Removal of fluoride from drinking water by natural stilbite zeolite modified with Fe(III). Desalination 2011;121-127.

[34] Brown GE, Henrich VE, Casey WH, Clark DL, Eggleston C, Felmy A, Goodman DW, Grätzel M, Maciel G, McCarthy MI, Nealson KH, Sverjensky DA, Toney MF, Zachara JM. Metal oxide surfaces and their interactions with aqueous solutions and microbial organisms. Chem Rev 1998;77-174.

[35] Abdus-Salam N., Itiola A.D. Potential application of termite mound for adsorption and removal of $\mathrm{Pb}$ (II) from aqueous solutions. J Iran Chem Soci 2012;373-382.

[36] Altundo HS, Tümen F. Removal of phosphates from aqueous solutions by using bauxite II: The activation study. J Chem Technol Biotechnol 2003;824-833.

[37] Ho YS, McKay G. Pseudo-second order model for sorption processes. Process Biochem 1999;451-465.

[38] Biswas K, Gupta K, Ghosh UC. Adsorption of fluoride by hydrous iron(III)-tin(IV) bimetal mixed oxide from the aqueous solutions. Chem Eng J 2009;196-206.

[39] Cornell RM, Schwertmann U. The Fe oxides-structure, properties, reactions, occurrence and uses, VCH Verlagsgesellschaft, VCH Publishers, New York. 1996.

[40] D. F. Shriver, P. W. Atkins, Langford CH. Inorganic Chemistry, Oxford University Press. 1994.

[41] Guo H, Stüben D, Berner Z. Removal of arsenic from aqueous solution by natural siderite and hematite. Appl Geochem 2007;22:1039-1051.

[42] Liu Q, Guo H, Shan Y. Adsorption of fluoride on synthetic siderite from aqueous solution. J Fluor Chem 2010;635-641.

[43] [43] S. Ayoob, Gupta AK. Performance evaluation of alumina cement granules in removing fluoride from natural and synthetic waters. Chem Eng J 2009;485-491.

[44] Chen N, Zhang Z, Feng C, Li M, Zhu D, Sugiura N. Studies on fluoride adsorption of iron-impregnated granular ceramics from aqueous solution. Mater ChemPhys 2011;293-298.

[45] Thakre D, Rayalu S, Kawade R, Meshram S, Subrt J, Labhsetwar N. Magnesium incorporated bentonite clay for defluoridation of drinking water. J Hazard Mater 2010;122-130.

[46] Kagne S, Jagtap S, Dhawade P, Kamble SP, Devotta S, Rayalu SS. Hydrated cement: A promising adsorbent for the removal of fluoride from aqueous solution. J Hazard Mater 2008;88-95.

[47] Nikita Sakhare, S. Lunge, S. Rayalu, S. Bakardjiva, J. Subrt, Sukumar Devotta, Labhsetwar N. Defluoridation of water using calcium aluminate material. Chem Eng J 2012;406-414.

[48] Tripathy SS, Raichur AM. Abatement of fluoride from water using manganese dioxide-coated activated alumina. J Hazard Mater 2008;1043-1051.

[49] Kumar E, Bhatnagar A, Kumar U, Sillanp M. Defluoridation from aqueous solutions by nano-alumina: Characterization and sorption studies. J Hazard Mater 2011;1042-1049.

[50] Sujana MG, Thakur RS, Rao SB. Removal of fluoride from aqueous solution by using alum sludge. J Colloid Interface Sci 1998;94101.

[51] Solangi IB, Memon S, Bhanger MI. Removal of fluoride from aqueous environment by modified Amberlite resin. J Hazard Mater 2009;815-819. 
[52] Sari A, Tuzen M. Kinetic and equilibrium studies of biosorption of $\mathrm{Pb}$ (II) and $\mathrm{Cd}(\mathrm{II})$ from aqueous solution by macrofungus (Amanita rubescens) biomass. J Hazard Mater 2009;1004-1011.

[53] 53] Meenakshi S, Sundaram CS, Sukumar R. Enhanced fluoride sorption by mechanochemically activated kaolinites. J Hazard Mater 2008;164-172.

[54] McKay YG, Blair HS, JR G. Adsorption of dyes on Chitin. I. Equilibrium studies. J of Appl Polym Sci 1982;3043-3057.

[55] Nigussie W, Zewge F, Chandravanshi BS. Removal of excess fluoride from water using waste residue from alum manufacturing process. J Hazard Mater 2007;954-963.

[56] Chen N, Zhang Z, Feng C, Zhu D, Yang Y, Sugiura N. Preparation and characterization of porous granular ceramic containing dispersed aluminum and iron oxides as adsorbents for fluoride removal from aqueous solution. J Hazard Mater 2011;863-868. 